Original Research Article

\title{
A study of the histopathological changes in heart in electrocution deaths
}

\author{
Shubha. H V ${ }^{1}$, Nirmala. C. ${ }^{2}$ \\ ${ }^{1}$ Dr. Shubha. H V, Assistant Professor, Department of Pathology, Sapthagiri Institute of Medical Sciences and Research \\ Centre, Chikkasandra, Bangalore, ${ }^{2}$ Dr. Nirmala. C, Professor, Department of Pathology, Bangalore Medical College and \\ Research Institute, Bangalore.
}

Corresponding Author: Dr. Nirmala. C, Professor, Department of Pathology, Bangalore Medical College and Research Institute. E-mail id: drnirmala2018@gmail.com.

\begin{abstract}
Introduction: One of the biggest challenges faced by forensic pathologists is death due to electrocution. In almost half of all cases no gross pathological findings can be seen. The history surrounding the cause of death and circumstantial evidence is sometimes ambiguous and possesses great difficulty. Aim: To study the various histopathological changes in heart in electrocution. Methods and materials: In the present study, a total of 15 heart specimens in electrocution deaths and 15 normal heart specimens are considered during the study period of one year from 2015 to 2016. Case details are obtained from the records and analyzed. The histopathological findings are recorded in a proforma. Results: Myofibre break-up, separation of sarcomeres and extravasation of RBCs are found in all the 15 cases of electrocution (100\%). The other findings are disarray of the myofibres (87\%), hyper contracted myocyte with squaring of nuclei (73\%), myocellular segmentation (33\%) and myocyte vacuolization (20\%). Conclusion: The histopathological changes in heart definitely provide an additional clue in the diagnosis of electrocution deaths. Most of the histopathological changes in heart are found consistently in electrocution cases compared to that of the normal hearts. Hence, their presence can be relied upon in the diagnosis of electrocution deaths and in reducing the number of negative autopsies.
\end{abstract}

Keywords: Electrocution, Histopathology, Heart, Myofibre break-up.

\section{Introduction}

Electrocution is defined as death caused by the passage of electric shock into the body [1]. Electrocution deaths are not uncommon in forensic practice. One of the biggest challenges faced by forensic pathologists is death due to electrocution. In almost half of all cases no gross pathological findings can be seen. Even the history surrounding the cause of death and the circumstantial evidence is sometimes ambiguous and possesses great difficulty to the forensic pathologists. Thus, they might have to rely entirely on the histopathological findings of internal organs to conclude the cause of death [2].

Ventricular fibrillation is the most common mechanism of death in electrocution. But it is not clear if the fibrillation is due to purely electrophysiological changes or to identifiable structural abnormalities in the heart [3]. Although there are many studies related to the histopathological changes in skin in electrocution, little

Manuscript received: $10^{\text {th }}$ June 2018

Reviewed: $20^{\text {th }}$ June 2018

Author Corrected: $28^{\text {th }}$ June 2018

Accepted for Publication: $2^{\text {nd }}$ July 2018 is known about the morphological changes in heart. Hence, this study was undertaken with the objective of studying the various histopathological changes in heart in electrocution deaths and to look for the consistency of these findings in the cases, so that it can serve as an important aid in the diagnosis of electrocution deaths in future without anychance for ambiguity and thus, reducing the number of negative autopsies.

\section{Materialsand Methods}

Place of study: Pathology department of Bangalore Medical College and Research Institute

Duration of study: One year (2015-2016)

Type of study: Prospective study

Sampling method: Stratified random sampling

Sample collection: The material for the study was obtained from 15 heart specimens in cases with a definite entry wound of electrocution and 15 normal heart specimens with no history of cardiac disease which weresent for the histopathological examination. 
Inclusion criteria: Cases with adefinite electric contact mark (entry or exit mark) on the skin and cases with circumstantial evidence favoring electrocution death.

Exclusion criteria: Cases with a known cardiac disease condition as obtained from the detailed history.

Statistical tool: Microsoft Excel 2007 and IBM SPSS statistical analysis.

Ethical committee clearance was obtained for the study. A detailed history of the cases was obtained from the

\section{Original Research Article}

medical records. The details were recorded on a proforma. The specimens werepreserved in $10 \%$ neutral buffered formalin and sections were given from the representative areas of myocardium. They were subjected to histopathological tissue processing. The tissue sections were stained with Haematoxylin and Eosin. Microscopic examination was carried out to look for the various histopathological changes in the heart sections. These changes were recorded on a proforma and were compared with the findings of the normal heart. The results were analyzed using the statistical tool, namely Microsoft Excel 2007.

\section{Results}

The microscopic examination of the heart sections in cases of electrocution deaths revealed the following spectrum of histopathological changes: Myofibre break-up (100\%) (Figure 1), separation of the myofibres (100\%), haemorrhage with extravasation of RBCs (100\%) (Figure 2), disarray of the myofibres (87\%), hyper contracted myocyte with squaring of nuclei (73\%) (Figure 3), myocellular segmentation (33\%) and myocyte vacuolization (20\%) (Figure 4). These changes were found diffusely throughout the sections.

The normal heart sections showed only few similar histopathological findings such as myofibre break-up (33\%) and separation of the myofibres (20\%) which were not accompanied by haemorrhage with extravasation of RBCs. These findings were found only focally in the sections. None of the normal heart sections showed disarray of the myofibres, hyper contracted myocyte with square expression of the nuclei, myocellular segmentation or myocytevacuolization.

The myofibre break-up due to artifactual cause such as knife motion in cutting the histological sections was readily distinguished from the real changes as it was found only focally in the tissue sections and was not accompanied by haemorrhage with extravasation of RBCs or other changes.

Table-1: Histopathological changes in the heart in electrocution cases.

\begin{tabular}{|c|c|c|c|}
\hline & Histopathological changes & Frequency & Percentage \\
\hline 1. & Myofibrebreak-up (MFB) & 15 & 100 \\
\hline 2. & Separation of the myofibres & 15 & 100 \\
\hline 3. & Haemorrhage with extravasation ofRBCs & 15 & 100 \\
\hline 4. & Disarray ofthe myofibres & 13 & 87 \\
\hline 5. & Hypercontracted myocyte with square expression of the nucleus & 11 & 73 \\
\hline 6. & Myocellular segmentation & 05 & 33 \\
\hline 7. & Myocyte vacuolization & 03 & 20 \\
\hline
\end{tabular}

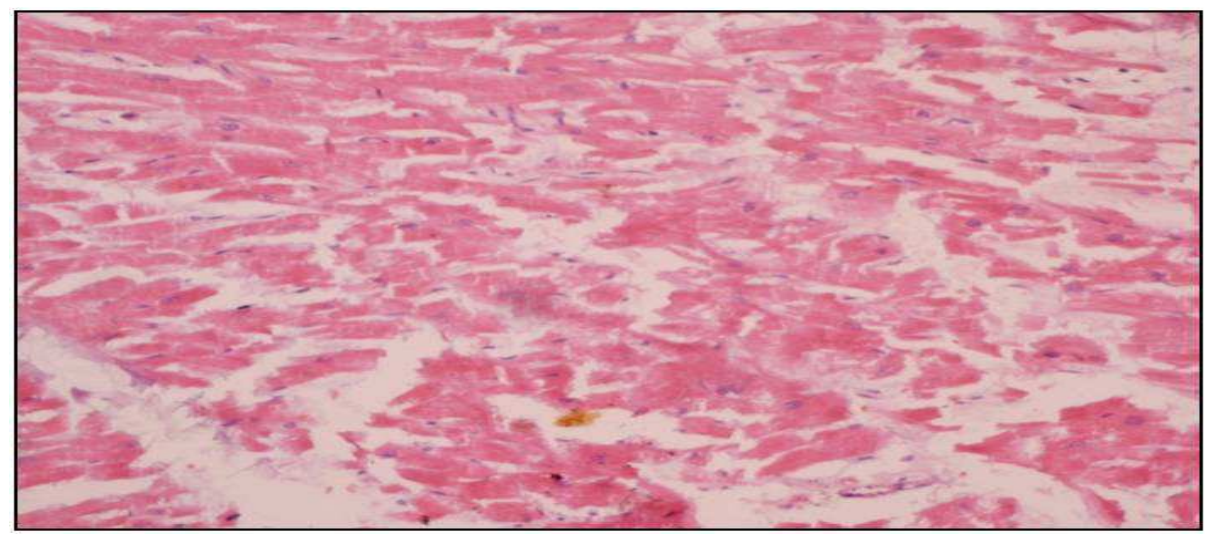

Figure 1: Myofibre break-up and disarray of the myofibres, H \&E stain, X100 


\section{Original Research Article}

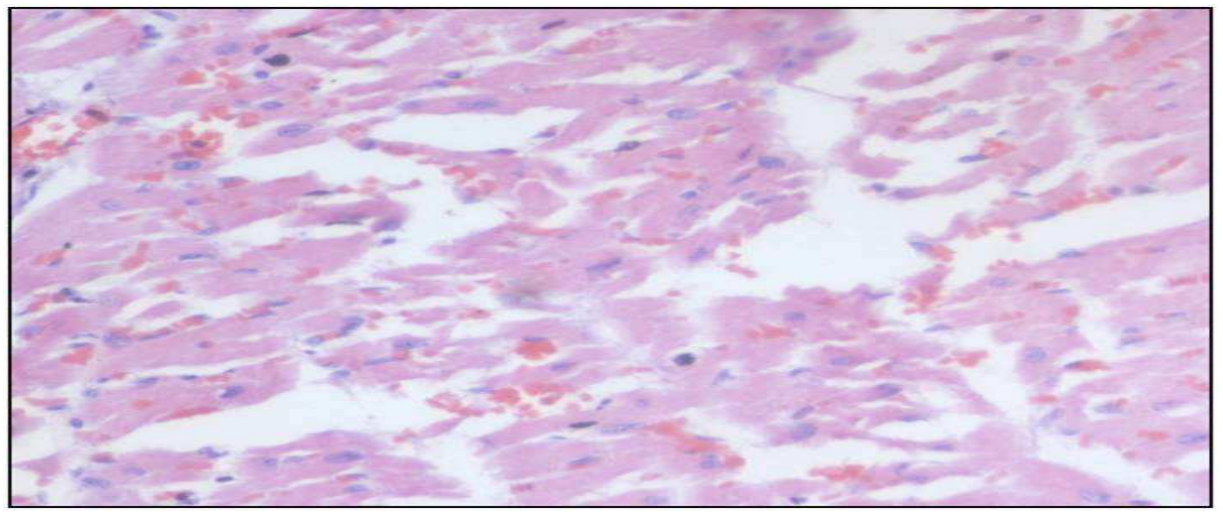

Figure-2: Extravasation of the RBCs and myofibrebreak-up, $H$ and $E$ stain, X100

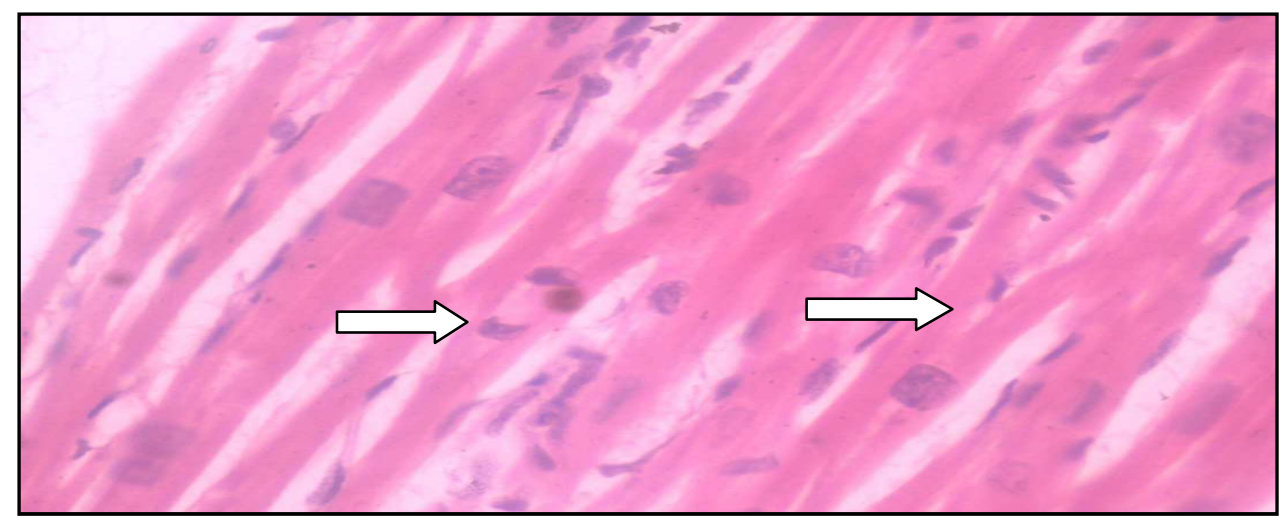

Figure-3: Square expression of the myocyte nuclei, $H$ and $E$ stain, X400

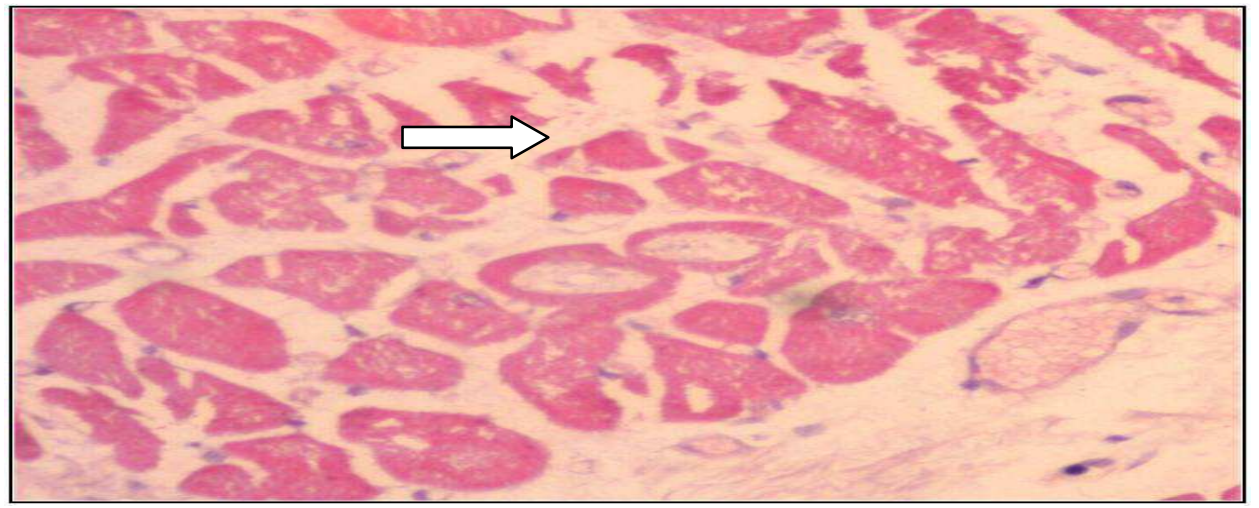

Figure-4: Myocyte vacuolization, $\mathrm{H}$ and $\mathrm{E}$ stain, $\mathrm{X} 400$

\section{Discussion}

The principal cause of death in electrocution is usually believed to be a disturbance in cardiac electric conduction leading to ventricular fibrillation. Ventricular fibrillation is defined a "chaotic, random, asynchronous electrical activity of the ventricles due to repetitive re-entrant excitation and/or rapid focal discharge"[4].

But it is not clear if the fibrillation is due to purely electrophysiological changes or to identifiable structural abnormalities in the heart. In electrocution deaths, however, the morphological alterations in the myocardium are poorly documented. Ku et al. Hypo the sized that electrocution can cause direct injury to the myocardium with resulting damage or induce coronary spasm with resulting myocardial infarction [5].

Electrical injury may affect the heart either by causing cardiac dysrhythmias or direct necrosis of the myocardium [6]. Though ventricular fibrillation is considered as the main cause of death following electric shock, electric injury sometimes can cause patchy necrosis of the myocardium [7,8,9]. It is generally accepted that any intervention that increases spatial inhomogeneity of heart muscle facilitates the induction of certain cardiac arrhythmias. Myofibre break-up is 


\section{Original Research Article}

certainly a possibility that must be considered in causing re-entry and electrical instability. It also provides structural substrate necessary to initiate chaotic electrical asynchronous activity.

Death due to electrocution is one of the listed causes for a negative autopsy. A negative autopsy is one in which after a thorough complete autopsy, chemical examination of all relevant internal organs, necessary histopathological and biochemical analysis, a definite cause of death cannot be found. The entry or exit wound may not be quite prominent many a time. The history surrounding death is also ambiguous. Therefore, characterizing the type \& frequency of structural myocardial changes is of immense help in the diagnosis of electrocution deaths.

In our study, a spectrum of histopathological changes were observed in the sections of heart in electrocutioncases.Among those changes, one of the most important findings is the myofibrebreak-up which was found with a frequency of $100 \%$. In a study conducted by Vittorio Fineschietal., the morphologic changes in the hearts of twenty-one subjects, who died instantaneously due toelectrocution were compared to the hearts of cases with different types of death. The frequency of myofibre break-up in cases of electrocution was maximal (90\%). Their findings showed that myofibre break-up is a characteristic antemortem histopathological finding in electrocution deaths $[10,11,12]$. In a case report by Stanca et al., myofibre break-up has been described in a 55 year old women who died of electric current effects [13].

The occurrence of myofibre break-up is debatable among the forensic pathologists. But the myofibre break-up seen due to knife motion in cutting can be easily distinguished from that due to electrocution. VanderweeMA et al, concluded in his study that myocytes contract just before actin and myosin become strongly linked to maintain the state of rigor mortis
[14]. Baroldi $\mathrm{G}$ et al., found that myofibre break-up was absent in all the cases autopsied after 1-24 hours. They also demonstrated the absence of myofibre break-up in all the hearts excised at transplantation [15]. This fact also argues against the possibility that myofibre breakup is an artifact, occurring secondary to histological processing.

In a study conducted by Luo BT et al., pathologic changes such as disarray of myocardial fibres, rupture of myocardial fibres and focal interstitial haemorrhage has been described [16]. In our study, haemorrhage was found in $100 \%$ of the cases and disarray of the myofibres in $87 \%$ of the cases.James TN et al., studied the hearts of four men who died from electrical accidents and in all the fourhearts there was wide spread focal necrosis involving all the myocardium and there was contraction band necrosis of smooth muscle cells in the tunica media of the coronary arteries. One of the hearts showed fibromuscular dysplastic narrowing of small coronary arteries [8].

Some of the other findings such as hypercontracted myocyte with square expression of the myocyte nuclei were seen in $73 \%$ of our cases. This characteristic finding has been mentioned by Fineschi et al. and in a case report by Dabas et al. [17]. In another study conducted by Viswakanth et al., microscopic myocardial findings like separation of myofibres, alternating hypercontracted-hyperdistended myocytes and squaring of the myocyte nuclei were reported in all the cases. Tanaka $\mathrm{N}$ et al. also has described diffuse fragmentation of the myocardium with myocardial nuclei in hyper contracted cells showing a square appearance [18]. Anil Agrawal has mentioned changes like plaque-like destruction, striate infarctions, haemorrhages, fine droplet fatty infiltrations, edema and fragmentation of cardiac muscle fibres [19]. In the present study, myocellularsegmentation due to rupture of intercalated discs $(33 \%)$ and myocyte vacuolization (20\%) were reported.

\section{Conclusion}

The histopathological changes in the heart definitely provide an additional clue in the diagnosis of electrocutiondeaths. Most of the histopathological changes described in our study were found consistently in the cases andhence, their presence in the sections can be relied upon in the diagnosis of electrocution deaths especially in theabsence of any external marks.

Need for the study: This study conclusively proves that electrocution produces its own specific microscopic changes in heart. Although there are many studies related to the histopathological changes in skin in electrocution, little is known about the changes in heart. Therefore, characterizing the type \& frequency of structural myocardial changes is of immense help in the diagnosis of electrocution deaths. This study plays a major contributory role in the diagnosis of electrocution deaths especially in the absence of circumstantial evidences and contact marks and helps in reducing the number of negative autopsies. 


\section{Original Research Article}

Funding: Nil, Conflict of interest: None initiated Permission from IRB: Yes

\begin{tabular}{|c|c|c|}
\hline \multirow{2}{*}{ Nature of work } & \multicolumn{2}{|c}{} \\
\cline { 2 - 3 } & \multicolumn{2}{|c|}{ AUTHORS } \\
\cline { 2 - 3 } & $\mathbf{1}$ & $\mathbf{2}$ \\
\hline Concepts & $\square$ & $\square$ \\
\hline Design & $\square$ & $\square$ \\
\hline Definition of intellectual content & $\square$ & \\
\hline Literature search & $\square$ & \\
\hline Data acquisition & $\square$ & $\square$ \\
\hline Data analysis & $\square$ & \\
\hline Statistical analysis & $\square$ & $\square$ \\
\hline Manuscript preparation & $\square$ & $\square$ \\
\hline Manuscript editing & $\square$ & $\square$ \\
\hline Manuscript review & $\square$ & $\square$ \\
\hline Guarantor & $\square$ & $\square$ \\
\hline
\end{tabular}

\section{References}

1. Taber CW, Venes D. Tabers cyclopedic medical dictionary, 20th ed. Philadelphia: F.A. Davis Co.; 2009.

2. Vishwakanth B, Shruthi P. Low voltage electrocution deaths and histo pathological findings: One-year prospective autopsy study. J. Curr. Forensic Sci Res. 2015; 1(2):1-5.

3. Fineschi V, Di Donato S,Mondillo S, Turillazzi E. Electric shock:Cardiac effects relativetonon fatal injuries and post-mortem findings in fatal cases. Int $\mathbf{J}$ Cardiol. 2006; 111(1):6-11. DOI: https://doi.org/ 10. 1016/j. ijcard.2005.07.060

4. Zipes DP. Electrophysiological mechanisms involved in ventricular fibrillation. Circulation 1975 Dec; 52(6):120-30.

5. Ku CS, Lin SL, Hsu TL, Wang SP, Chang MS. Myocardial damage associated with electrical injury. Am Heart J. 1989;118(3): 621-4. DOI: http://dx. doi.org/ 10.1016/0002-8703(89)90283-4

6. Koumbourlis AC. Electrical injuries. Crit Care Med. 2002; 30 (11): 24-30. DOI: http: //dx.doi.org/10.1097/ 00003246- 200211001-00007

7. Lewin RF, Arditti A, Sclarovsky S. Non-invasive evaluation of electrical cardiac injury. Br Heart J. 1983; 49:190-2. DOI: http://dx.doi.org/10.1136/hrt.49.2.190
8. James TN, Riddick L, Embry JH. Cardiac abnormalities demonstrated post-mortem in four cases of accidental electrocution and their potential significance relative to nonfatal electrical injuries of the heart. Am Heart J. 1990 Jul;120(1):143-57. DOI: https: // doi.org/10.1016/0002-8703(90)90171-S

9. Romero B, Candell-Riera J, Gracia RM, Fernandez MA, Aquade S, Peracaula R et al. Myocardial necrosis by electrocution: evaluation ofnon-invasive methods. J Nucl Med 1997;38(2):250-1.

10. Fineschi V, Karch SB, D'Errico S, Pomara C, Riezzo I, Turillazzi E. Cardiac pathology in death from electrocution. Int J Legal Med. 2006 Mar;120(2):79-82. DOI: https://doi.org/10.1007/s00414-005-0011-8

11. Uzun I, Akyildiz E. Histo pathological differentiation of skin lesions caused by electrocution, flame burns and abrasion. Forensic Sci Int. 2008; 178 (2-3): 157-61. DOI: http: //dx.doi.org/10.1016/j. forsciint. 2008.03.012

12. Fontanarosa PB. Electrical shock and lightning strikes. Ann Emerg Med. 1993;22(2):378-87. DOI: http: //dx.doi.org/10.1016/S0196-0644(05)80468-8

13. Stanca L, Zavoi R, Marinescu AM, Niculescu M, Stanculescu D. Cardiac morphological changes in electrocution. Rom J Leg Med 2007;15(2):100-5. DOI: https://doi.org/10.4323/rjlm.2007.100 


\section{Original Research Article}

14. Vanderwee MA, Humphrey SM, Gavin JB, Armiger LC. Changes in the contractile state, fine structure and metabolism of cardiac muscle cells during the development of rigor mortis. Virchows Arch B Cell Pathol Incl Mol Pathol. 1981;35(2):159-67. DOI: 10. 1007/BF02889156.

15. Baroldi G, Silver MD, Parolini M, Pomara C, Turillazzi E, Fineschi V. Myofiber break-up: a marker of ventricular death. Int J Cardiol. 2005;100(3):435-41.

16. Luo BT, Zhao YH, Chen XY, Jiang HG. Pathology of accidental electrocution: an autopsy study of 16 cases. Chinese J Pathol. 2009 Jun;38(6):380-3. DOI: 10.3760/cma.j.issn.0529-5807.2009.06.006
17. Dabas N, Bakkannavar SM, Bhat S, Palimra V. Microscopic cardiacchanges in an electrocution death. $\mathrm{J}$ Punjab Acad Forensic Med Toxicol. 2015;15 (2): 93-6.

18. Tanaka N, Kinoshita, Jamal M, Kumihashi M, Tsutsui K, AmenoK. Findings for current marks: histopathological examination and energy-dispersive Xray spectroscopy of three cases. Leg Med. 2013 Sep; 15 (5):283-7. DOI: https://doi.org/10.1016/j. legalmed. 2013.06004

19. Aggrawal A. Textbook of forensic medicine and toxicology, $1^{\text {st }}$ ed. APC India (P) Ltd.;2014.

\section{How to cite this article?}

Shubha. H V, Nirmala. C.A study of the histopathological changes in heart in electrocution deaths. Trop J Path Micro 2018;4(3):236-241.doi:10. 17511/jopm.2018.i3.01 